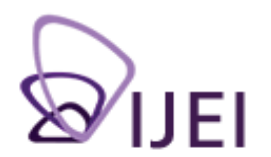

International

Journal for

Educational

Integrity

\title{
Responses to student plagiarism in higher education across Europe
}

\author{
Irene Glendinning \\ Coventry University, UK \\ ireneg@coventry.ac.uk
}

Keywords: Student plagiarism, academic integrity, plagiarism survey, research ethics, academic conduct, European Higher Education

Previous versions of this paper have been presented at the $5^{\text {th }}$ International Integrity and Plagiarism Conference, Newcastle-upon-Tyne, UK, 16-18 July 2012 and the Plagiarism Across Europe and Beyond Conference, Brno, Czech Republic, 12-13 June 2013. The current version represents a substantially revised and updated account of the research undertaken by the IPPHEAE project.

\begin{abstract}
A significant amount of research has been undertaken in response to high levels of student plagiarism in higher education institutions (HEI). New models have emerged over the last decade for strategies and systems for detection, penalties and mitigation, based on deeper understanding of the underlying reasons behind student plagiarism. Most research has been initiated by academics from English speaking countries, particularly from the UK, North America and Australia.
\end{abstract}

When the proposal for the Impact of Policies for Plagiarism in Higher Education across Europe (IPPHEAE ) project was developed during 2009 very little research had been conducted about the policies for academic integrity adopted by HEls in the majority of countries in Europe. IPPHEAE, funded by the European Commission (2010-2013), included a comparative study of policies and procedures in place in HEls across 27 European Union (EU) member states for handling aspects of academic integrity, focusing specifically on bachelor and master's levels. The survey instruments were on online questionnaires, student focus groups, structured interviews and analysis of documentary evidence, designed with a view to capture a range of quantitative and qualitative responses from different perspectives.

Almost 5,000 responses were captured for the survey, mainly from online questionnaires, made available in 14 languages. Different questions were asked of students, teaching staff and senior managers, to determine how well institutional procedures were understood, to what extent they were operating as intended and whether there was consistency of outcomes within and between institutions.

Interviews with researchers and people associated with national bodies and agencies responsible for higher education (HE) quality or academic integrity explored broader perspectives on issues such as national policies and how responses to plagiarism aligned with policies for quality and standards.

This paper presents results from the survey that focus specifically on institutional policies, highlighting examples of good practice and also areas of concern. The findings suggest that different approaches should be adopted according to the maturity of existing policies and systems in all the countries surveyed, to promote more effective assurance of quality, standards and academic integrity.

The International Journal for Educational Integrity is available online at:

http://www.ojs.unisa.edu.au/journals/index.php/IJEI/

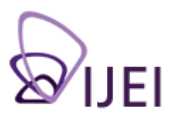




\section{Introduction}

This paper reports on research undertaken for the project Impact of Policies for Plagiarism in Higher Education Across Europe (IPPHEAE), which was funded through the European Commission's Lifelong Learning Programme, under the Modernisation of Higher Education agenda during 2010-2013. The project was designed to investigate how student plagiarism was being addressed in Higher Education Institutions (HEls) throughout 27 countries of the European Union (EU).

The research was designed to fill the gap in the knowledge about policies and procedures for maintaining standards of academic integrity at bachelor and master's levels in different parts of Europe. The survey explored whether policies were being applied as intended and whether they were fit for purpose. However, the project was also concerned with applying knowledge and ideas emerging from the research and sharing examples of effective strategy, policies, procedures and resources, to influence regions and institutions where there was seen to be less engagement with challenges presented by student plagiarism and academic misconduct.

This paper reports on the EU-wide IPPHEAE survey, detailing the research methodology, design and implementation. Results about institutional policies are presented, with reference to some of the data collected from different sources. The key findings are discussed together with a summary of the recommendations and conclusions for EU overall.

\section{IPPHEAE project context}

The IPPHEAE project operated from October 2010 until September 2013, with a consortium of five institutions. The author was principal investigator, leading a team from Coventry University (CU), UK, and partners from Lodz University of Technology, Poland, Mendel University, Brno, Czech Republic, Aleksandras Stulginskis University, Lithuania (ASU) and University of Nicosia, Cyprus. UK plagiarism expert, Jude Carroll, contributed to the project in a consultancy capacity. A challenging aspiration of the IPPHEAE project was that "Influencing national and local strategy will be much harder, but not impossible".

Research activities for the project comprised three major strands: a cross-Europe survey of HEls, the subject of this paper; development of software tool ANTON for searching a national e-library archive; and in-depth case studies of interventions, strategies and policies in selected countries and HEls across the EU.

\section{Review of literature}

The focus of earlier research into plagiarism and academic dishonesty has spanned reasons for plagiarism, investigations about attitudes and also policies for addressing plagiarism, including the implementation of digital tools. Earlier research into policies was initiated by academics in English speaking countries, particularly UK, North America and Australasia (for example, Bretag et al., 2011; East, 2009; Tennant \& Duggan, 2008; Tennant \& Rowell, 2010).

Some researchers, notably McCabe, have particularly focused on the attitudes to plagiarism in North America (2005) and Canada (Abasi \& Akbari, 2008). A few researchers have investigated plagiarism in European countries, particularly Sweden (Carroll \& Zetterling, 2009, Pecorari \& Shaw, 2012; Razera, Verhagen, Pargman, \& Ramberg, 2010). Hayes and Introna (2005) explored cultural influences to plagiarism in international students studying in an English university, drawing comparisons between students from UK, Asia, Greece and China. 
Procedures and policies in UK HEls are the subject of several publications (Carroll, 2006; Macdonald \& Park, 2004; Morris, 2011; Neville, 2010), which commonly advocate a holistic institutional response to academic integrity. The evidence from this wide range of research has increased understanding of why plagiarism occurs, proposed different methods for dealing with different breaches to academic integrity and suggested what can be done to encourage good scholarship.

Recent Swedish research has included innovative ways of applying software tools for similarity checking (Appelgren Heymann, Olofsson, Hansson, Moberg, \& Illsson, 2012; Larsson \& Hansson, 2012). Pataki reported on a research project about the development of search tools and techniques for addressing the prevalence of plagiarism in Hungary by translation of sources from other languages (2012). Plagiarism by translation also featured in a paper by Sousa-Silva from Portugal that focused on a forensic detection approach using linguistic analysis (2013).

In several countries software tools and resources were being developed for aiding the detection of plagiarism. Hungary, Czech Republic, Slovakia, Poland and Lithuania were found to be at different stages of developing national digital libraries of postgraduate theses and supporting systems for making use of the established repositories for aiding the detection of student plagiarism (Chudá, Lačný, Maršalek, \& Sũkenik, 2013; Veselý \& Kolomaznik, 2013; IPPHEAE reports for Lithuania, Poland and Czech Republic).

Blogs and Wikis provided a rich source of information about plagiarism policies in some EU universities, but it emerged that some contributors chose to remain anonymous for fear of intimidation. Several blogs contained topical developments about high profile plagiarism cases, but also highlighted systemic failures and encouraged reform of policies across all levels of higher education governance (Archeologie-Copier-Coller, Copy-Shake-Paste, Le Plagiat.net, Plagionintitutkija Blogspot, Vroniplag Wiki). Some of these sites disseminated research results, for example comparing anti-plagiarism software tools (Weber-Wulff \& Isolen, 2012).

\section{Methodology}

As the literature review suggests, prior to the IPPHEAE project very little information was available about the nature and effectiveness of policies and procedures for dealing with plagiarism or academic dishonesty in the majority of HEls in EU countries. The EU-wide survey was designed to capture evidence of current practices by exploring views at four levels covering a sample of HEls in all $27 \mathrm{EU}$ member states. Information was collected from students (bachelor and master's level), academic teaching staff, senior management, people with responsibility nationally for quality or academic integrity, and documentary sources at national and institutional levels.

A few questions from earlier research were found to be applicable to this research, for example exploring Why do students cheat? (Park, 2003, pp. 479-480) and investigations into self-reported plagiarists (Hayes \& Introna, 2005, pp. 219-222). However, most IPPHEAE survey questions were designed specifically for this study. Draft surveys were checked, translated and piloted within partner institutions as a paper-based exercise. The final versions of the surveys were then released for full language translations.

The scale and volume of the data collection, the geographical scope and range of languages for participants made it essential to have online questionnaires designed for quantitative analysis. Questions for senior managers were available both as a structured interview and online questionnaire with language translation. The senior management survey had fewer, mainly open questions compared to student and 
teacher questionnaires. Some questions for national participants were similar to those for senior management, with some additional questions exploring national educational strategies. The interviews were conducted face-to-face, by Skype, telephone, and occasionally by email.

In order to ensure the questions were understood by EU participants, 14 language versions of the online questionnaires were created, and phrasing and nature of questions varied according to intended respondents and the survey method.

Question wording needed to be understood when translated across languages and any jargon meaningfully and consistently interpreted in different educational systems and cultures. For teacher and student questionnaires many questions use a five-point Likert scale with rubric from 'strongly disagree' to 'strongly agree'. Responses from students and teachers were coded and language-neutral, reducing the need for retranslation into English, although additional free-text feedback was invited for most questions.

A mapping of similar questions across the different survey methods ensured that responses could be compared for analysis and evaluation. The survey questions were based on the following themes:

- understanding and awareness of academic integrity

- $\quad$ experiences of plagiarism and academic dishonesty

- $\quad$ knowledge of institutional policies, systems and procedures for academic integrity

- views on plagiarism deterrence and detection

- $\quad$ understanding academic writing conventions

- institutional characteristics for assessment and study

- national initiatives for academic integrity.

Considering the potentially sensitive nature of the data being collected, the use of coding helped to secure the required level of anonymity for encouraging participation of both individuals and institutions. 'Informed consent' forms and associated guidance notes were made available to participants in different languages and built into the online questionnaires.

It was important to try to capture feedback from a representative sample of the student population in different types of HEls in every EU country to try to obtain a set of institutional profiles that could be compared within a country and between countries. However the reluctance of many institutions to participate in the research made a comprehensive EU-wide investigation of HEls unrealistic. Instead an opportunistic sample of responses was collected from participants and HEls in each country who were willing to complete the survey, drawn from the very large number $\mathrm{HEls}$ and individuals contacted. Student participants from each $\mathrm{HEl}$ could be a mixture of residents from the country being studied, from other EU countries and international non-EU students.

Reports were prepared for the $27 \mathrm{EU}$ member states, summarising the survey responses and also drawing on previous research, government reports and online materials. National survey participants provided reviews and feedback for these reports. Each report incorporated a set of recommendations nationally, institutionally and for individual academics.

The findings from the 27 country reports were combined to provide an EU-wide comparative summary of policies and procedures for plagiarism and academic misconduct in different countries. All reports are available via the project website. 


\section{Research findings}

Almost 5,000 responses to the survey were received in total. The online questionnaire responses were reorganised from the language sets into country datasets, then coded and made anonymous of individuals and institutions.

For some countries the relatively small sample size compared to overall HE student population sizes and the low number of participating institutions made it impossible to draw any general conclusions from the data. However, the responses provided an interesting snapshot from which to formulate some useful recommendations.

Student responses for each country were typically largely from students normally resident there plus a small number of international students studying in that country. Although the research focus was on bachelor and master's students, participants were from all HE levels, covering a wide range of subject disciplines. Responses from people working and studying outside the $27 \mathrm{EU}$ countries were not included in the analysis.

Notably the profile of UK students differed from that of other countries with $51 \%$ of UK student respondents from outside the EU and only $25 \%$ normally resident in the UK. The UK ratios reflect the student populations of many universities, particularly affecting postgraduate level.

\section{Monitoring, reviewing and revising cases of academic misconduct}

Of the teachers' responses across all EU countries 9\% strongly disagreed and $14 \%$ disagreed with the statement Our national quality and standards agencies monitor plagiarism and academic dishonesty in HEls with $52 \%$ not sure, $18 \%$ agreeing and $4 \%$ strongly agreeing. However, in other evidence from teachers and national and senior management participants it emerged that very few EU countries had implemented national level policies and procedures for monitoring aspects of academic integrity at bachelor and master's levels.

In Sweden HEls have been required to provide annual statistics for the government agency on the number and type of academic misconduct cases, which were summarised every four years in a national report (Högskoleverket, 2011). Although this system of monitoring is to be welcomed to provide some insight into national trends and progress in academic integrity, survey participants questioned the accuracy and comparability of the institutional data.

National participants from Austria also spoke of national policy and systems. However, only $11 \%$ of Austrian teachers responded positively to the statement Our national quality and standards agencies monitor plagiarism and academic dishonesty in $\mathrm{HEls}$, with $56 \%$ not sure and $22 \%$ disagreeing. Of Austrian teachers responding to the question about who monitors plagiarism policies and procedures (tick all that apply): $5 \%$ selected By the national quality agency, $17 \%$ selected By our institutional quality manager, $34 \%$ opted for At faculty or subject level and $47 \%$ of participants said they did not know. These responses suggested that any national policy and systems in place in Austria were not effectively communicated.

By comparison, of the responses from teachers in UK and the Republic of Ireland (Rol) to the same question about who has responsibility $14 \%$ of UK and $13 \%$ of Rol teachers selected monitoring by national quality agency; $55 \%$ of UK and $50 \%$ from Rol chose institutional quality manager, $55 \%$ of UK and $31 \%$ of Rol selected monitoring at faculty or subject level; and $29 \%$ UK, $25 \%$ Rol said they did not know. This feedback and other supporting evidence from national and institutional responses suggest that most institutions in the UK and Rol had policies in place for 
academic integrity and that cases of academic misconduct and plagiarism were normally recorded at some level (departmental or institutional). However, as was the case with all other countries in the survey, many of the UK and Rol responses indicated that there was little confidence in the consistency between and sometimes within institutions about what data was recorded and at what level it was held, and no means of comparing similar statistics across institutions.

Many teacher respondents said they did not know at what level their policies for plagiarism were monitored (45\%), reviewed $(50 \%)$ and revised $(54 \%)$. The most commonly selected level for policy responsibility was faculty or subject level $(41 \%$ monitoring $34 \%$ reviewing and $25 \%$ revising). The strongest response to this question was from UK teachers confirming that policy monitoring most often takes place at institutional (55\%) and faculty or subject level (55\%), with responsibility for reviewing policy also split between institutional (51\%) and faculty/subject levels $(51 \%)$, but revision of policy was more likely to be conducted at institutional level $(55 \%)$ than faculty/subject level (39\%).

\section{Policies and procedures}

Survey responses suggest that most of the institutions engaged in the survey had some policies at institutional or departmental level for academic misconduct and plagiarism. However several contacts from different EU countries declined to respond to the survey, saying their institution had no effective systems in place. This factor introduces a degree of bias in the data collected towards reporting on institutions that have positive messages or more mature practices.

In response to the statement This institution has policies and procedures for dealing with plagiarism $35 \%$ of all EU teachers agreed and $36 \%$ strongly agreed, with $14 \%$ not sure and $14 \%$ disagreeing. On considering country responses a less positive picture emerged (25-100\% respondents disagreeing) in Italy, Spain, France, Portugal, Belgium, Finland, Bulgaria and Germany although the low response rate for some countries made it impossible to draw general conclusions.

According to feedback from interviews, Finland and parts of Germany were planning to introduce national or regional standards and policies for research ethics at postgraduate and post-doctoral levels, but these were at a relatively early stage and there little evidence emerged of active systems for monitoring or enforcement. The Hungarian Accreditation Committee (HAC) responsible for quality monitoring in higher education, established and published their 2013-2015 strategy for auditing the quality process and systems of HEI (Füzessi, 2013). However, this appeared to be a missed opportunity as the strategy made no mention of academic integrity.

Some countries had national policies in place or had been supported nationally for acquiring digital tools for aiding plagiarism detection (UK, Finland, Austria, Sweden and Slovakia). The UK's JISC Electronic Plagiarism Project is a particularly pertinent example of how a national initiative for digital tools in HEls had a lasting impact on institutional policies (Rowell, 2009).

In the largest of the German Bundesländer, NordRhein-Westfalen (NRW) the Rectors Konferenz for Fachhochshculen has published a policy for using software to detect plagiarism (HRK, 2012). However it emerged that in most EU countries it is uncommon for essays, formative work and written assignments to be subjected to digital checks. Where tools were in use, typically only the final student thesis was checked.

A report was published for the French Minister of Higher Education and Research about fraud in higher education (Mazodier, Foucault, Blemont, \& Kesler, 2012), in which section 3 concerned plagiarism. The report made clear that France lagged 
behind some other European countries (naming Norway and UK) in having no visible policies for examination fraud and plagiarism and advocated a more cohesive, consistent and proportional policy response for France.

From Bulgaria one respondent stated "here there are no measures" and that there is "not a single case of a student being dismissed for plagiarism". However, other responses from teachers and students suggest that some Bulgarian institutions do have policies and procedures in place.

Most EU participants were against the idea of having national or regional policies or directives to institutions for responding to plagiarism, favouring preservation of institutional autonomy. However in some countries, particularly France, Germany, Bulgaria, and Romania, participants advocated introducing a set of national guidelines across all HEls to kick-start the process of institutional reform for developing policies to respond to plagiarism.

\section{Responsibilities for identifying misconduct cases}

Teachers were asked about where the responsibility rests for decisions on culpability for student plagiarism, inappropriate collusion and exam cheating.

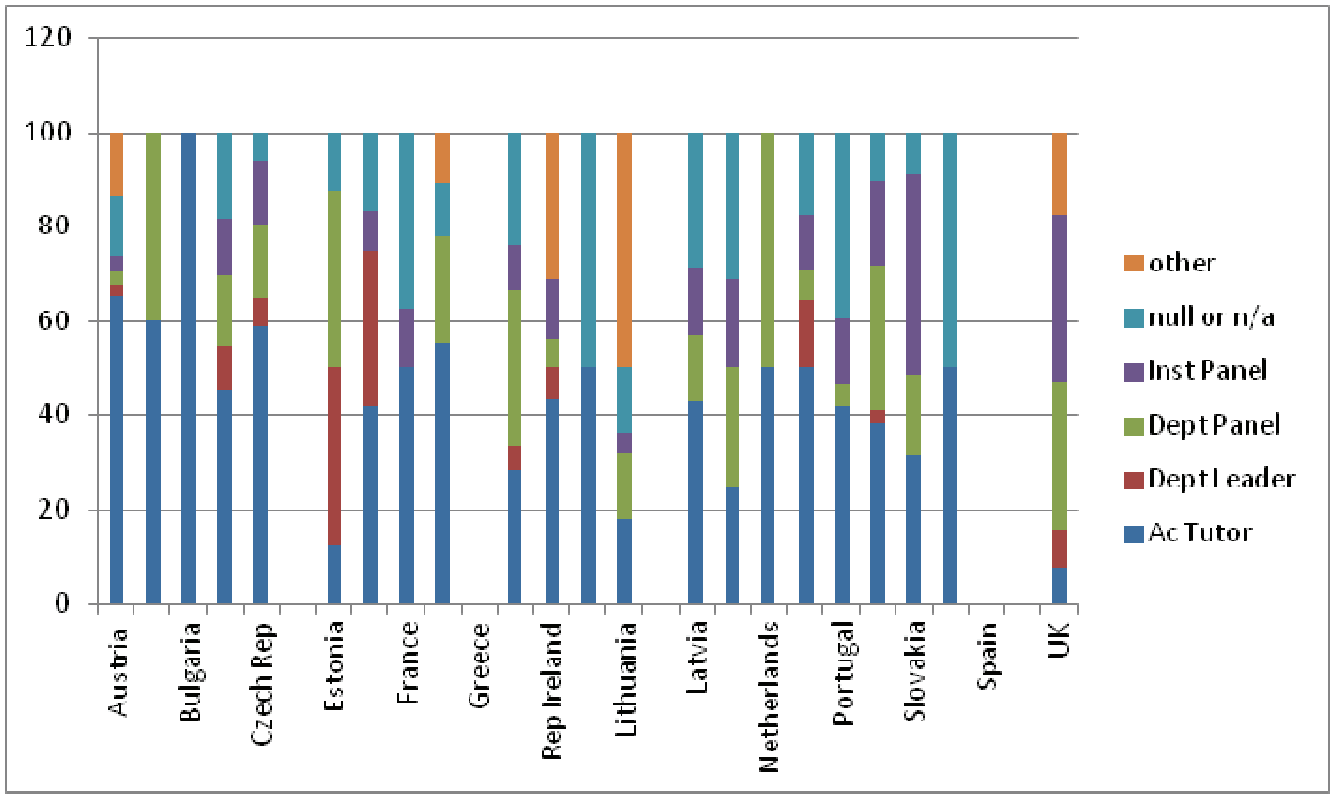

Figure 1: Teachers' responses to: Who decides whether a student is guilty of plagiarism?

Concerning who takes decisions about whether a student has committed plagiarism, Figure 1 shows that the individual academic tutor ( $47 \%$ of EU teachers) was by far the most commonly selected option. In some institutions it emerged that a committee or panel took the decision on whether plagiarism had occurred, either at departmental or institutional level (as is the case in Sweden). Figure 1 shows teachers' responses for most EU countries. In 'other' feedback $6 \%$ of teachers said the responsibility rested with an individual, often the dean, dean of students or rector.

The responses from UK teachers show a very distinct difference with only $8 \%$ of participants selecting the academic tutor. In some institutions in UK and Rol teachers, managers and national responses indicated that an institution-wide system of trained experts had been established to respond in a timely, consistent and systematic way to breaches in academic integrity. These posts were normally 
departmentally based and typically called Academic Conduct Officers (ACOs), following Macdonald and Carroll (2006) and documented in UK national guidance (Morris 2013).

When teachers were asked who takes decisions on exam cheating the responses were very similar to those in Table 1 for plagiarism, but with more teachers $(55 \%)$ selecting the academic tutor option than for decisions on cases of plagiarism.

The responses to the question about inappropriate collusion showed differences to plagiarism and exam cheating. Overall $38 \%$ of respondents selected the academic tutor, $7 \%$ said the departmental leader made the decision, $13 \%$ overall said an institutional panel was responsible, $13 \%$ said departmental panel, with null responses from $23 \%$ of respondents. Again deans, ACOs and rectors were mentioned in $6 \%$ 'other' feedback.

\section{Responsibilities for deciding on sanctions for academic dishonesty}

The responses from EU teachers (Table 1 and Figure 2) suggest that for Plagiarism the sanctions or penalties were most likely to be decided by an institutional panel $(26 \%$ overall). For exam cheating (30\%) and inappropriate collusion (21\%) the responsibility for sanctions most commonly rests with the academic tutor (Table 1 ) according to EU teachers.

Interview feedback at institutional and national level suggested that collusion between students was not viewed as a problem in some countries, but instead was often seen as the normal way students support each other in their learning. This may be reflected by almost half of respondents selecting not applicable $(23 \%)$ or not responding to the question (24\%) concerning decisions and penalties for collusion (Table 1).

In many countries institutions are free to set their own penalties for misconduct (for example Bulgaria, UK, Rol, Romania, Spain, Cyprus, France, Germany, Lithuania). In Finland and Sweden the penalties are restricted to a formal warning letter or a period of suspension, between one week and one year, after which the student would normally continue their programme. According to participants from both countries, in rare cases when a suspension was applied it was normally at the low end of this range and the hearing could be almost a year after the decision was taken to investigate.

Table 1:

Teachers' responses EU-wide: Who decides on sanctions for academic misconduct?

\begin{tabular}{|l|c|c|c|c|c|c|c|}
\hline & Null & $\begin{array}{c}\text { Academic } \\
\text { tutor }\end{array}$ & $\begin{array}{c}\text { Department } \\
\text { Leader }\end{array}$ & $\begin{array}{c}\text { Department } \\
\text { panel }\end{array}$ & $\begin{array}{c}\text { Institution } \\
\text { panel }\end{array}$ & Other & $\begin{array}{c}\text { Not } \\
\text { applicable }\end{array}$ \\
\hline Plagiarism & $9 \%$ & $17 \%$ & $15 \%$ & $20 \%$ & $26 \%$ & $6 \%$ & $8 \%$ \\
\hline $\begin{array}{l}\text { Exam } \\
\text { cheating }\end{array}$ & $7 \%$ & $30 \%$ & $12 \%$ & $13 \%$ & $18 \%$ & $3 \%$ & $3 \%$ \\
\hline $\begin{array}{l}\text { Inappropriate } \\
\text { collusion }\end{array}$ & $11 \%$ & $21 \%$ & $13 \%$ & $17 \%$ & $20 \%$ & $5 \%$ & $13 \%$ \\
\hline
\end{tabular}

Students and teachers were asked: What would happen if a student at your institution was found guilty of plagiarism in their assignment? Table 2 summarises the responses.

Some respondents said that the penalty would depend on the severity of the offence. The most common penalties selected were rewriting the work, zero mark and verbal warning. The 'other' feedback indicated that sometimes new work or a different project must be completed, often with the initial assessment having been awarded zero or 
reduced mark. In some regimes a 'cap' was imposed to limit the final mark, typically to the threshold pass mark. However, in some institutions students resubmitting work had access to the same range of marks or grades as for their first attempt (national interviews Romania, Bulgaria).

The percentages of teacher and student responses (Table 2) were similar for the lighter sanctions, but there were differences of perception concerning the application of more serious sanctions. This result suggests that there may be a deterrent effect in evidence, because student respondents tended to think the sanctions were more draconian than they actually were.

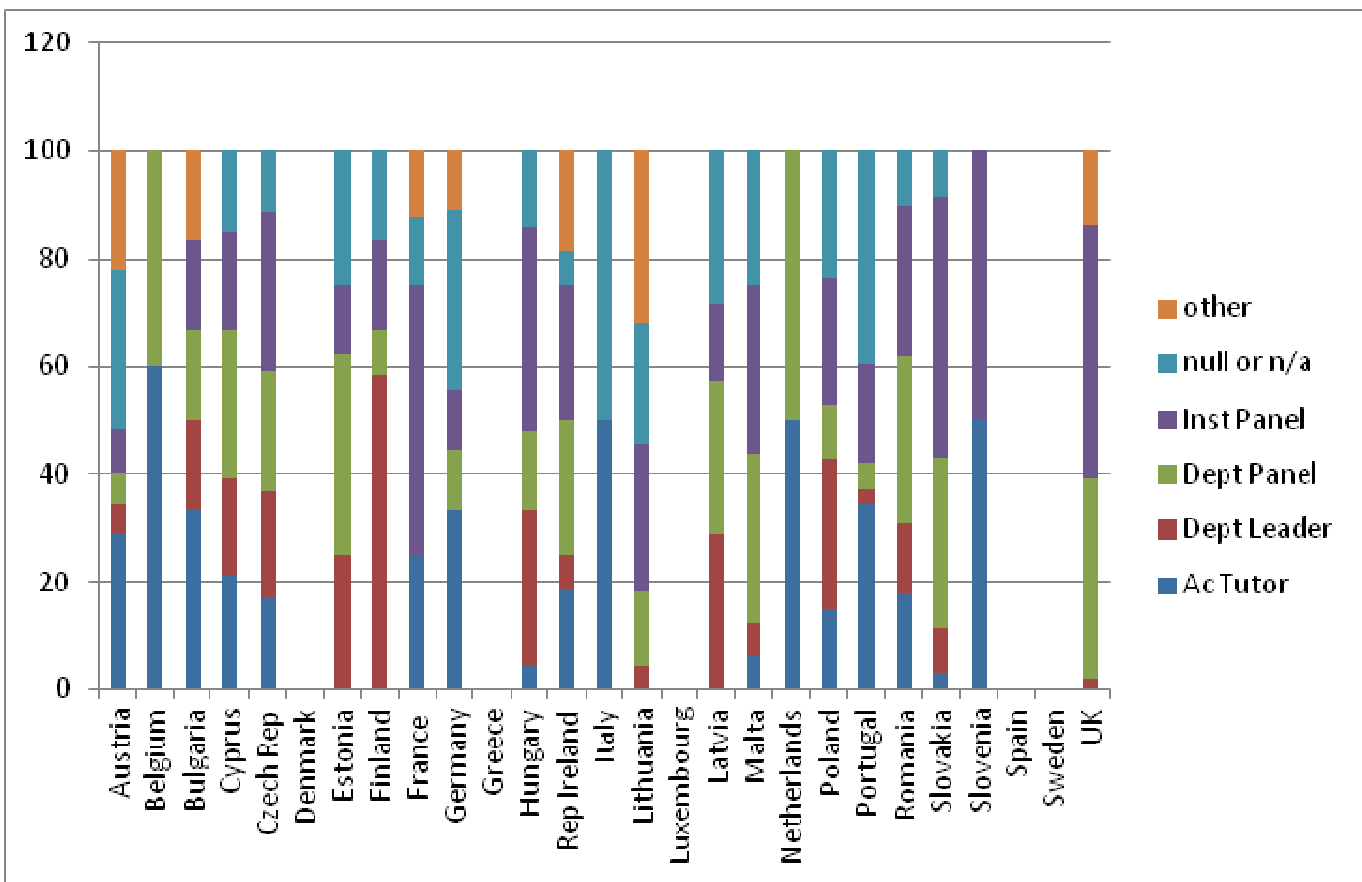

Figure 2: Teacher responses to: Who decides on the penalty applied to students for plagiarism

Table 2:

Sanctions for plagiarism: EU-wide Responses

\begin{tabular}{|c|c|c|c|c|}
\hline \multicolumn{2}{|c|}{ Assignment } & \multicolumn{2}{|c|}{ Project or Dissertation } & \multirow{2}{*}{$\begin{array}{l}\text { Students } n=3906 \\
\text { Teachers } n=687\end{array}$} \\
\hline Student & Teacher & Student & Teacher & \\
\hline $21 \%$ & $16 \%$ & $5 \%$ & $5 \%$ & No action would be taken \\
\hline $50 \%$ & $48 \%$ & $15 \%$ & $20 \%$ & Verbal warning \\
\hline $27 \%$ & $17 \%$ & $27 \%$ & $20 \%$ & Formal warning letter \\
\hline $52 \%$ & $54 \%$ & $35 \%$ & $49 \%$ & Request to re write it properly \\
\hline $54 \%$ & $52 \%$ & $42 \%$ & $42 \%$ & Zero mark for the work \\
\hline $38 \%$ & $33 \%$ & $26 \%$ & $25 \%$ & Repeat the module or subject \\
\hline $38 \%$ & $30 \%$ & $28 \%$ & $24 \%$ & Fail the module or subject \\
\hline $11 \%$ & $6 \%$ & $19 \%$ & $10 \%$ & Repeat the whole year of study \\
\hline $13 \%$ & $9 \%$ & $33 \%$ & $21 \%$ & Fail the whole programme or degree \\
\hline $14 \%$ & $5 \%$ & $19 \%$ & $9 \%$ & Expose the student to school community \\
\hline $14 \%$ & $8 \%$ & $29 \%$ & $18 \%$ & Suspended from the institution \\
\hline $12 \%$ & $2 \%$ & $30 \%$ & $4 \%$ & Expelled from the institution \\
\hline $13 \%$ & $1 \%$ & $20 \%$ & $2 \%$ & Suspend payment of student grant \\
\hline $11 \%$ & $8 \%$ & $10 \%$ & $8 \%$ & Other \\
\hline
\end{tabular}


The JISC funded AMBeR project investigated penalties in place for different categories of academic dishonesty across different institutions in the UK (Tennant \& Duggan, 2008) and then proposed a tariff of penalties for different types of academic dishonesty that could be adopted nationally by institutions (Tennant \& Rowell, 2010). Although this tariff has not been adopted universally by UK institutions, the research feedback from UK and Rol national participants suggested that this research often formed part of the body of evidence considered during institution or department reviews of policy.

\section{Strategies for discouraging plagiarism and academic dishonesty}

The most commonly mentioned prevention strategy for academic dishonesty was the use of digital 'plagiarism detection' tools. Many teachers, senior managers and national respondents (UK, Rol, Finland, Germany, Austria) implied that providing this facility together with the threat of sanctions was a sufficient deterrent. In particular three UK senior management respondents expressed confidence that there was no problem with consistency in detection or decision-making because a standard procedure required all work to be submitted through text matching tools.

In formal trials (Weber-Wulff \& Isolen, 2013) and practical experience reported by some respondents (national interviews Finland, UK, Germany), it has been established that software tools in use have different strengths and limitations that can vary according to the language. Characteristics of some European languages (for instance Finnish) can make it easy to deceive the algorithms for matching. Sometimes matching was hampered by an immature or incomplete repository of sources. Some tools relied on an institution-based repository therefore could not match to external sources. Respondents reported that a few of the tools need further investment to begin to match the capabilities and reach of the commercial market leaders. It appears from the survey evidence that misplaced confidence in the capability of software tools has led to some complacency through over-reliance on software as the primary means of both discouraging students from plagiarising and detecting it when it arises.

Encouragingly, overall for the EU, $47 \%$ of teachers agreed and $31 \%$ strongly agreed that it is possible to design coursework to reduce student plagiarism, with $14 \%$ not sure and $6 \%$ disagreeing and this agreement was reflected in most country responses, with more negative responses from Czech Republic (24\%), Belgium (20\%) and Slovakia (17\%). 'Designing out' techniques recommended in 'other' feedback included deploying active rather than passive learning approaches that naturally lead to application of knowledge and different outputs for each student or team. Several respondents alluded to research about formative use of digital tools during classes for academic writing and research skills (following research of Davis, 2009; Ireland \& English, 2011).

In the case of theses or project work the close relationship with the supervisor was viewed by many respondents to be the best way to determine the originality of the students work. This factor was reflected in the recent report to the French government: "The best technique to prevent plagiarism is organizing frequent appointments between teacher and student throughout the dissertation writing or thesis and of course regular oral questions about some details of the work presented" (translated from Mazodier et al., 2013, p. 45). However, such approaches were refuted as impracticable by a Hungarian respondent who asserted that it was impossible to include labour-intensive assessment practices with class sizes of 500 and a Swedish respondent agreed that this was impractical with large numbers of supervisees.

Communication with all stakeholders about the policies, procedures and consequences of plagiarism are essential elements of strategies for deterring academic dishonesty. The high percentage of respondents (students and teachers) 
across all countries who were not sure about policies and systems in their own institution indicates that more should be done to disseminate and inform academic communities about policies that directly affect them. However, given the many respondents at all four levels who asserted that the majority of student plagiarism is accidental, there was a clear acceptance about the need to develop academic writing skills, promote good academic conduct and practice and instil ethical values.

There were mixed views on what development and training was currently being offered within institutions and what more could be done, for example some teachers in Germany expressed disbelief at the idea that professors needed any further training. Some respondents said they already provided high quality student and staff development sessions in this area. However, most of the respondents over all countries accepted that better access to knowledge of policies and further training in academic integrity was essential for both staff and students.

\section{Efficacy of policies for academic integrity}

Uncertainty was expressed by respondents from across the EU about effectiveness of institutional policies because of lack of statistics and other evidence. One participant from Finland said that plagiarism was "commonly known so they should be doing something about it". According to a participant from Germany "There are no institution -wide policies, therefore it can't be effective", "even if you tell them about plagiarism they will still do it", but the "use of software tools [to aid detection of plagiarism] is seen as a threat" by students. In Bulgaria "the penalty code ... defines plagiarism as a crime, but as with most of these regulations, this is just on paper" (national interview).

In several countries there had been recent developments in academic integrity policies, but initiatives typically focused on postgraduate and post-doctoral levels, for example Finnish Universities of Applied Sciences (polytechnics) were required to publish theses on an open repository called Theseus.

Information from interviews and documentary sources in several counties (including Sweden, Greece) highlighted that cheating in examinations was a big problem, often through a lax approach to invigilation. In France: "It was reported to us by so many doctors they had passed all exams of the second to sixth grade in a lecture theatre surrounded by the same friends" (Mazodier et al., 2012, p. 33, translated); and in Bulgaria exam cheating was described through various means including use of hidden technology (national interview).

It was suggested that the culture of rote learning in some institutions encouraged students to memorise notes for examinations, discouraging critical thinking and innovation. It emerged that where this was normal practice, plagiarism in essays and dissertations was not viewed as wrong by students and often condoned by teachers, particularly at undergraduate level (student focus group, France).

A more optimistic message came from Rol citing: "evidence that [policies] are much more effective than they were" (national interview, Rol). However, further evidence, based on two interviewees' contact with other HEls, implied that some Rol institutions may have less effective policies for academic integrity than those involved in the research.

It is important to recognise the maturity of policies and systems in much of the UK following significant investment in research and development starting about 2002. Teams and individuals from several UK HEls implemented and evaluated strategies and policies for responding to plagiarism (for example universities of Lancaster, Oxford Brookes, Northumbria). The excellent practices have permeated down to many UK HEls and have influenced other countries. Responses from many UK participants included reference to this research and confirmed that institution-wide 
policies have been introduced in recent years based on the holistic institutional 'Oxford Brookes Model', involving Academic Conduct Officers (Carroll, 2005; Macdonald \& Carroll, 2006) and variations on the AMBeR Tariff (Tennant \& Rowell, 2010).

A high level of awareness was evident across UK national participants about the need for strategic approaches for detecting, responding and discouraging plagiarism. Most UK national interviewees were far from complacent, accepting that the nature of the threat to academic standards from plagiarism and other forms of academic dishonesty evolves over time, requiring HEls to adapt their systems and processes accordingly. This was particularly true of UK institutions with a high percentage of international students acknowledging that the extent to which academic writing conventions are understood varies according to previous educational experience (Davis, 2009; Hayes \& Introna, 2005; Robinson-Pant, 2009).

Conversely, clear evidence emerged that in a small number of UK institutions, typically some of the research intensive universities, there was no way of knowing how individual academics responded to suspected cases of plagiarism, because no system of oversight or uniform policy existed for dealing with assessment, academic dishonesty or plagiarism in different parts of the institution. A common theme emerging from national interviews was that professors strongly defended their high degree of academic autonomy and there was little opportunity to challenge their decisions on either assessment or academic integrity. A similar picture emerged from parts of Germany, France, Finland and Bulgaria.

Several participants from different countries made reference to 'the press' as a direct influence on awareness about plagiarism at all levels of education, citing high profile cases of plagiarism including the Romanian and Hungarian Prime Ministers and two national German government ministers (Vroniplag Wiki).

Seventy per cent of senior management respondents expressed doubt about consistency of approach to penalties for student plagiarism. The following response from the UK suggests a number of reasons for lack of uniformity:

Most teachers follow the system, but some find ways around it, ignore cases of plagiarism mainly don't care, too lazy to be bothered, or think they can deal with it themselves. Sometimes tutors who are not native English speakers find it difficult to spot plagiarism, but Turnitin can help them; interviews with colleagues for research have provided evidence to support my views. (national interview UK)

\section{Continuing threats to academic integrity}

Experience in the UK, Ireland and Australia has demonstrated that, even after strong preventative measures have been taken and robust policies and procedures have been strictly applied, plagiarism and academic dishonesty will remain a threat to academic standards. There will always be the need to remain vigilant and to respond to new and evolving threats.

It was reported that in some countries, such as Lithuania, Romania, Czech Republic and Bulgaria, the low pay and lack of job security forces academics to take second and third jobs. In other countries such as Hungary, Spain and Italy, large class sizes make personal contact with students difficult. As several participants indicated, such factors increase the prospect that plagiarism and academic dishonesty cases may not be detected or appropriately addressed. 
The prevalence of ghost-written student work was of concern to several respondents. However other interviewees had no knowledge of this phenomenon and seemed oblivious that students may be submitting work that was not their own. The ghost writer may be a friend, colleague or relative, or students may commission work to order from a so-called 'paper mill' for payment. Although the clear intent to defraud elevates the seriousness above normal plagiarism, the lack of originality may not be detected by software tools or by manual checks. As some respondents indicated, ghost-writing can present a particularly difficult problem when assessing distance learning programmes. More generally, it is no known how much ghost-written work is currently going undetected in higher education assessment.

The continuum between genuinely original student work and ghost-writing can include aspects of proofreading, editing and even translation between languages. Where the borderline lies between acceptable practice and plagiarism is a grey area for both students and teachers. In the 2010 annual report of the Office of the Independent Adjudicator, the ombudsman for student complaints in England and Wales called for HEls to develop policy in the light of "Lord Woolf's landmark Inquiry Report into the LSE's [London School of Economics] links with Libya", that presented a "key challenge for all universities to remove ... ambiguities associated with permissible assistance for postgraduate study" (OIA, 2011, p. 5). The Woolf report referred to allegations that former LSE student Saif Gaddafi received an unfair level of external support for preparing his $\mathrm{PhD}$ thesis (Woolf, 2011). The OIA report recommended "removing ambiguity, clarifying guidance and enforcement of the rules of academic misconduct not only help to protect the reputation of universities, but... also protect the interests of the student" (OIA, 2011, p. 6).

It is clear from the survey feedback that many students and teachers have observed examples of plagiarism from academic colleagues and also from prominent people in public life. The need for public figures and academic staff to set a clear example to young people about what constitutes good practice in writing and research has never been greater.

\section{Discussion}

Many institutions had policies and procedures implemented for dealing with plagiarism at institutional or departmental level, but well informed participants in each country confirmed that not all these policies were enforced or applied consistently. In addition, based on feedback from national authorities and from the questionnaires, it emerged that there were HEls in every country surveyed with no coherent strategies or policies implemented for dealing with plagiarism.

Evidence emerged of heightened awareness within the last two years at national level particularly in Germany, Finland, France, Romania, Hungary, Luxembourg and Austria that actions need to be taken across the HE sector to respond to the threats to academic integrity. However, in some other countries including Belgium, Spain, Italy, Greece, Netherlands, there was reluctance to contribute to the research and very little evidence was found of developments in HE strategy and policy at any level.

Whatever the assessment regime, the academic teacher is at the front line for identifying possible irregularities and makes an initial decision about whether there needs to be further investigation. Individualism and lack of transparency leads to inconsistencies of student outcomes and unless there is some moderation process it can be inherently unfair to students.

Great variability in understanding what constitutes plagiarism and what was deemed acceptable academic practice was very evident in responses to several questions. Participants from different countries (particularly Germany and Finland) had 
encountered situations where students were encouraged to directly embed writing of their supervisor in their own work, a practice which would be considered to be plagiarism in most academic circles. Conversely there were cases raised of academic supervisors who published results from their students' research without acknowledgement.

Apart from the high profile bloggers mentioned earlier, several participants with interest in plagiarism research said they were viewed by colleagues as troublemakers or whistle-blowers, preferring to keep a low profile. Several interviewees from Bulgaria, Finland, France and Germany expressed fear of the consequences of identification by colleagues for participating in the research. Evidence emerged of coercion and intimidation by academic colleagues, asking them to drop cases of plagiarism or to be softer in their approach, much of this was anecdotal but a few cases were supported by documentation (Moore, 2008). It is not helpful for fear and stigma to be associated with activities connected with upholding academic standards.

On a lighter note, the research revealed many excellent initiatives in the areas of developing effective systems for detecting, managing and discouraging plagiarism and academic dishonesty. A great deal of good practice emerged from the survey responses concerning designing-out plagiarism through effective pedagogy and assessment strategies, some of which was unpublished. Several suggestions concerned adopting a positive stance towards scholarship and the joy of learning rather than emphasising what not to do: "It is about creating a culture of intellectual curiosity and honesty - leading by example" (senior manager UK).

When asked to describe good practice, many respondents referred to early work led by UK academics including Jude Carroll, Chris Park and Colin Neville, which provided a solid basis of good practice that is still being applied today in helping to understand the complex nature of plagiarism. There were also many references to funding from JISC for the AMBeR project tariff, plagiarism.org and guidance from the Higher Education Academy for England and Wales (Morris, 2011). All such initiatives continue to have profound impact far beyond the UK.

Surprisingly, responses from national interviews, teachers and senior managers confirmed that none of the EU national or regional quality and standards agencies systematically monitored or audited either the effectiveness of policies or the number of academic misconduct cases arising. However the terms of reference for most of these organisations, for example the UK's Quality Assurance Agency (QAA) and recently reorganised agencies in Sweden and Hungary, provide the remit to do this if they so choose.

\section{Conclusions}

This research revealed new information about how different EU institutions and countries were responding to the challenge of student plagiarism in the internet age. The data for some countries is limited, which make it difficult to generalise. However the simple act of contacting an institution to discuss research, even if they chose not to participate, helped to elevate the issue of how plagiarism was being handled, encouraging reflection and action. It was apparent that all participating institutions viewed high levels of plagiarism and academic dishonesty as problematic and people were interested in the research and in hearing about the results of the project.

The findings confirmed that HEls in many parts of Europe had poorly defined policies and systems for assurance of academic integrity. In some countries and institutions where policies were in place, there was little evidence of monitoring and review. The lack of comparable statistics was seen by many participants as a great impediment to 
understanding the 'big picture'. However, making policies stronger and more consistent is a prerequisite for generating comparable statistics.

Perhaps the greatest impediments to progress in academic integrity across the EU are the lack of consensus over what constitutes plagiarism, differences in academic standards, expectations of academic tutors and educational priorities. It is hoped that the IPPHEAE research and recommendations will help to highlight ways to begin to address the ineffectiveness and voids in policies and provide a focus for national and institutional education leaders.

The recommendations to the $27 \mathrm{EU}$ countries varied according to an assessment of the maturity of their current situation, based on the survey results. Many examples of innovative practice emerged from the research, which countries and institutions with less developed policies have been asked to consider adapting for local needs.

The IPPHEAE team knows that this research has already made a small but important contribution to understanding the European landscape of academic integrity, but a great deal more work needs to be done to move towards an equitable EU system for higher education, particularly in terms of consistency of quality and standards.

\section{References}

Abasi, A. R., \& Akbari, N. (2008). Are we encouraging patchwriting? Reconsidering the role of pedagogical context in ESL student writers' transgressive intertextuality. English for specific purposes, 27(3), 267-284. Retrieved from http://www.sciencedirect.com/science/article/pii/S0889490608000045.

Appelgren Heyman, F., Olofsson, M., Hansson, H., Moberg, J., \& Ilsson, U. (2012). Can we rely on text originality check systems? Proceedings of the $5^{\text {th }}$ International Plagiarism Conference, Newcastle upon Tyne, July.

Borg, E. (2009). Local plagiarisms. Assessment and Evaluation of Higher Education, 34(4), 415-426.

Bretag, T., Mahmud, S., East, J., Green, M., James, C., McGowan, U., Partridge, L., Walker, R., \& Wallace, M. (2011). Academic integrity standards: A preliminary analysis of the academic integrity policies at Australian universities. Australian Universities Quality Forum, 29 June-1 July, Melbourne, Australia.

Carroll, J. (2005). Handling student plagiarism: Moving to mainstream. Brookes eJournal of Learning and Teaching, 1(2). Retrieved March 26, 2012, from http://bejlt.brookes.ac.uk/vol1/volume1issue2/perspective/carroll.html.

Carroll, J., \& Zetterling, C. (2009). Guiding students away from plagiarism. KTH Learning Lab.

Chudá, D., Lačný, J., Maršalek, M., \& Sũkenik, J. (2013). Plagiarism detection in Slovak texts on the web. Proceedings of Plagiarism across Europe and Beyond, Brno, Czech Republic June.

Weber-Wulff, D. (2013). French rabbi steps down in plagiarism scandal. Copy-ShakePaste [web log]. Retrieved June 26, 2013, from http://copy-shakepaste.blogspot.de/2013/04/french-rabbi-steps-down-in-plagiarism.html

Davis, M. (2009). The role of Turnitin within the formative process of EAP: A tool for global academic culture. Proceedings of the BALEAP 2007 Conference.

Darde, J. N. (2013). Archeologie-Copier-Coller [web log]. Retrieved September 17, 2013, from http://archeologie-copier-coller.com/

East, J. (2009). Aligning policy and practice: An approach to integrating academic integrity. Journal of Academic Language and Learning, 3(1), A38-A51.

Füzessi, K. (2013). Higher education under threat in Hungary. Open democracy. Retrieved February 11, 2013, from http://www.opendemocracy.net/k\%C3\% A1roly-f\%C3\%BCzessi/higher-education-under-threat-in-hungary 
Hayes, N., \& Introna, L. D. (2005). Cultural values, plagiarism and fairness: When plagiarism gets in the way of learning. Journal of Ethics and Behaviour, 15(3), 213-231.

Högskoleverket. (2011). External review of the evaluation activities of the Swedish National Agency for Higher Education - Self-evaluation report. Swedish National Agency for Higher Education.

HRK Hochschulrektorenkonferenz. (2012). Zur Qualitätssicherung in Promotionsverfahren - Empfehlung des Präsidium der HRK an die promotionsberechtigten Hochschulen. [For quality assurance in the doctoral process - the recommendations of the Bureau of the German Rectors' Conference to doctorate awarding institutions]. Retrieved March 12, 2013, from http://www.hrk.de/uploads/

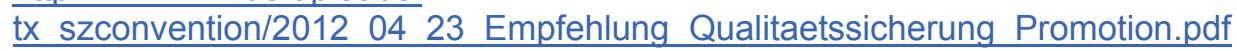

Hungarian Accreditation Committee. (2013). HAC Strategy 2013-15. Retrieved July 24, 2013, from http://www.mab.hu/web/index.php?lang=en

Impact of Policies for Plagiarism in Higher Education Across Europe project. (n.d.). Retrieved from http://ippheae.eu

Ireland, C., \& English, J. (2011). Let them plagiarise: Developing academic writing in a safe environment. Journal of Academic Writing, 1(1), 165-172.

JISC Electronic Plagiarism Project. (n.d.). Retrieved April 23, 2013, from http:// www.jisc.ac.uk/whatwedo/programmes/plagiarism/archive/detection.aspx

Larsson, K., \& Hansson, H. (2012). Anti-plagiarism control of thesis work - selection and integration of anti-plagiarism software SciPro. Proceedings of the $5^{\text {th }}$ Plagiarism Conference, Newcastle-upon-Tyne, July.

Maurel-Indart, H. (n.d.). Le Plagiat [web log]. Retrieved September 17, 2013, from http://leplagiat.net/

McCabe, D. L. (2005). Cheating amongst college students: A North American perspective. International Journal for Academic Integrity, 1(1). Retrieved March 26, 2012, from http://ojs.ml.unisa.edu.au/index.php/IJEl/article/viewFile/14/9

Macdonald, R., \& Carroll, J. (2006). Plagiarism: A complex issue requiring a holistic institutional approach. Assessment and Evaluation in Higher Education, 31(2), 233-245.

Mazodier, M., Foucault, M., Blemont, P., \& Kesler, S. (2012). La fraude aux examens dans l'enseignement supérieur - Rapport à Monsieur le minister de l'Enseignement supérieur et de la Recherche [Examination fraud in higher education - Report to the Minister of Higher Education and Research].

Moore, E. (n.d.) Plagionintitutkija [web log]. Retrieved September 17, 2013, http:// plagiointitutkija.blogspot.co.uk/

Moore, E. (2008). The four stages of addressing plagiarism. Transactions $3^{\text {rd }}$ International Plagiarism Conference, Newcastle. Retrieved February 5, 2013, from http://www. plagiarismadvice.org/research-papers/item/the-four-stages-ofaddressing-plagiarism

Morris, E. (2011). Policy works. Higher Education Academy for England. Retrieved May 6, 2013, from http://www.heacademy.ac.uk/assets/documents/ academicintegrity/policy works.pdf

Neville, C. (2010). The complete guide to referencing and avoiding Plagiarism. Open University Press.

Office of the Independent Adjudicator. (n.d.). Retrieved May 24, 2013, from http:// www.oiahe.org.uk/decisions-and-publications/public-interest-cases/

Office of the Independent Adjudicator. (2011). Annual Report 2011. Retrieved May 24, 2013, from http://oiahe.org.uk/media/57882/oia annual report 2011.pdf

Park, C. (2003). In other (people's) words: Plagiarism by students - literature and lessons. Assessment \& Evaluation in Higher Education, 28(5), 471-488.

Park, C. (2004). Rebels without a cause: Towards an institutional framework for dealing with student plagiarism. Journal of Further and Higher Education, 28(3), 291-306. 
Pataki, M. (2012). A new approach for searching for translated plagiarism. Proceedings of the $5^{\text {th }}$ Plagiarism Conference, Newcastle-upon-Tyne, July.

Pecorari, D., \& Shaw, D. (2012). Types of student intertextuality and faculty attitudes. Journal of Second Language Writing, 21, 149-164.

Razera, D., Verhagen, H., Pargman, T. C., \& Ramberg, R. (Eds.). (2010). Plagiarism awareness, perception and attitudes among students and teachers in Swedish higher education - A case study. Proceedings from the 2010 JISC Plagiarism Conference Newcastle, UK.

Robinson-Pant, A. (2009). Changing academies: Exploring international PhD student perspectives on 'host' and 'home' universities. Higher Education Research \& Development, 28(4), 417-429.

Rowell, G. (2009). A national strategy for ensuring authenticity in student work. EDULearn13 Conference, Barcelona, Spain 6-8 July.

Sousa-Silva, R. (2013). Investigating academic plagiarism: A forensic approach to plagiarism detection. Proceedings of Plagiarism across Europe and Beyond, Brno, Czech Republic, June.

Tennant, P., \& Rowell, G. (2010). Benchmark plagiarism tariff for the application of penalties for student plagiarism and the penalties applied. Retrieved http:// www.plagiarismadvice.org/resources/institutional-approaches/item/tennantbenchmarkreport

Tennant, P., \& Duggan, F. (2008). Academic misconduct benchmarking research project: Part 2. The recorded incidence of student plagiarism and the penalties applied. UK: The Higher Education Academy and JISC.

Veselý, O., \& Kolomaznik, J. (2013). Predicting number of search engine results to optimise online plagiarism detection. Proceedings of Plagiarism across Europe and Beyond, Brno, Czech Republic, June.

Vroniplag wiki. (n.d.). Retrieved April 30, 2014, from http://de.vroniplag.wikia.com/wiki/ Home

Weber-Wulff, D., \& Isolen, G. (2012, July 2). Uncovering scientific plagiarism. The Signpost. Retrieved March 10, 2013, from http://en.wikipedia.org/wiki/ Wikipedia:Wikipedia Signpost/2012-07-02/Analysis

Woolf. (2011). The Woolf inquiry: An inquiry into the LSE's links with Libya and lessons to be learned. Retrieved September 17, 2013, from http:// www.woolflse.com/dl/woolf-lse-report.pdf

\section{About the author}

Irene Glendinning is Academic Manager for Student Experience for the faculty of Engineering and Computing at Coventry University. She is principal Investigator for the Lifelong Learning Project 'Impact of Policies for Plagiarism in Higher Education Across Europe' 2010-2013, funded by the European Commission. Her research interests include quality assurance, student diversity and equality, pedagogy, student employment and employability. She has been an academic in higher education since 1990, with extensive experience of programme management covering a range of disciplines and lecturing in computer science. Earlier in her career she was a systems analyst and computer programmer and taught at secondary school level and in adult education. 